\title{
La Crónica abreviada de don Juan Manuel en la historiografía post-alfonsí
}

The Crónica abreviada of Don Juan Manuel in the Context of Post-Alphonsine Historiography

\author{
José Ángel Salgado Loureiro \\ Universidad de Santiago de Compostela (USC) \\ asalgadoloureiro@gmail.com
}

\section{Resumen}

El estudio de la Crónica abreviada estuvo tradicionalmente vinculado a la crítica de su fuente, la Estoria de España de Alfonso X. En el análisis e interpretación de la obra, los trabajos se han centrado especialmente en aspectos textuales o literarios. Respecto a la figura de don Juan Manuel como autor, se pueden identificar dos líneas de estudio principales. Una que lo ha relacionado con la cronística nobiliaria post-alfonsí, detractora de la ideología regia castellana, y otra que se ha centrado en el aprovechamiento de la imagen autoral del "Rey Sabio". En este texto examinamos el anclaje textual e ideológico de la Crónica abreviada dentro de la cronística post-alfonsí. Para ello presentamos un enfoque de carácter historiográfico que nos permita comprender la realidad de don Juan Manuel como cronista post-alfonsí a inicios del siglo XIV.

\section{Palabras clave}

Crónica abreviada, historiografía post-alfonsí, Estoria de España, don Juan Manuel.

\begin{abstract}
The study of the Crónica abreviada has been traditionally linked to the criticism of its principal source, the Estoria de España by Alfonso X. In the analysis and interpretation of the work, the experts have focused mostly upon textual or literary aspects. Regarding the figure of Don Juan Manuel as an author, two main lines of study can be identified. The one that has related him to the noble post-alfonsí chronicler, detractor of the Castilian royal ideology, and the other focused upon the use of the authorial image of the "Learned King". In this article we shall tackle the textual and ideological rationale of the Crónica abreviada within the post-Alphonsine chronicle. To that purpose, we present an historiographic approach to understand the reality of Don Juan Manuel as a post-Alphonsine chronicler in the early 14 th century.
\end{abstract}

\section{Keywords}

Crónica abreviada, post-Alphonsine historiography, Estoria de España, don Juan Manuel. 


\section{Introducción}

La Crónica abreviada es el resumen de la Estoria de España de Alfonso X que compuso don Juan Manuel entre 1320 y 1325, coincidiendo con el periodo en que fue tutor de Alfonso XI durante su minoría de edad. El texto se conserva únicamente en el ms. 1356 BNM, aunque tenemos noticia de un segundo manuscrito, hoy perdido, que habría pertenecido al Marqués de Mondéjar y cuyo contenido no sería igual al del que hoy conocemos ${ }^{1}$.

El arranque del estudio crítico sobre el ms. 1356 BNM se puede situar en la transcripción de algunos capítulos realizada por Ramón Menéndez Pidal en su edición de la Leyenda de los infantes de Lara, considerándolo una de las piezas clave para estudiar la Estoria de España. ${ }^{2}$ El trabajo de Pidal dio pie a los decisivos estudios de Diego Catalán, quien en 1977 publicó un trabajo con el título de "Don Juan Manuel ante el modelo alfonsí: el testimonio de la Crónica abreviada", 3 que en 1992 incluyó como capítulo en su estudio sobre la creación y evolución de la Estoria de España. ${ }^{4}$ Avanzando en sus planteamientos, en 1997 publicó De la silva textual al taller historiográfico alfonsí: códices, crónicas, versiones y cuadernos de trabajo, aunque aquí el protagonismo de la Crónica abreviada no es tan evidente a simple vista. ${ }^{5}$

A lo largo de su labor, Catalán consolidó un grupo de investigadores de la Universidad Autónoma de Madrid entre los que se encuentran algunos de los críticos actualmente más reconocidos en el estudio de la historiografía alfonsí y post-alfonsí, como Juan Bautista Crespo o Inés Fernández-Ordóñez. Sus trabajos han ofrecido una sólida estructura para localizar la Crónica abreviada en el mapa de la historiografía medieval castellana. ${ }^{6}$

En lo que respecta al análisis e interpretación de la Crónica abreviada, Carmen Benito-Vessels estudió cuestiones como su género literario o sus técnicas narrativas y compositivas. ${ }^{7}$ Entre los estudios más recientes destacamos el de Pablo Enrique

\footnotetext{
${ }^{1}$ Germán Orduna, "Los prólogos a la Crónica abreviada y al Libro de la caza: la tradición alfonsí y la primera época en la obra literaria de don Juan Manuel", Cuadernos de Historia de España, 51-52 (1970): 124-125.

2 Ramón Menéndez Pidal, Le leyenda de los infantes de Lara (Madrid: Centro de Estudios Históricos, 1934), 52-54. Para la transcripción de los capítulos véanse las páginas 245-247.

${ }^{3}$ Diego Catalán, "Don Juan Manuel ante el modelo alfonsí: el testimonio de la Crónica Abreviada”, en Juan Manuel Studies, ed. Ian MacPherson (Londres: Tamesis, 1977), 17-51.

${ }^{4}$ Diego Catalán, La Estoria de España de Alfonso X, creación y evolución (Valencia: Soler, 1992), 197229.

5 Diego Catalán, De la silva textual al taller historiográfico alfonsí. Códices, crónicas, versiones y cuadernos de trabajo (Madrid: Fundación Ramón Menéndez Pidal-Universidad Autónoma de Madrid, 1977). Destaca, no obstante, la hermosa dedicatoria de libro a don Juan Manuel como autor de la Crónica abreviada, quien "no escatimó tiempo de su vida en leer la obra del rey su tío con el espacio que merecía".

${ }^{6}$ Para este trabajo, de este autor destacamos: Juan Bautista Crespo, "La Estoria de España y las crónicas generales," en Alfonso X el Sabio y las Crónicas de España, ed. Inés Fernández-Ordóñez (Valladolid: Centro para la Edición de los Clásicos Españoles, 2000), 107-132; e Inés Fernández-Ordóñez, "La historiografía alfonsí y post-alfonsí en sus textos. Nuevo panorama", Cahiers de linguistique hispanique médiévale, 18-19 (1993): 101-132.

${ }^{7}$ Véanse los trabajos: Carmen Benito-Vessles, Don Juan Manuel: escritura y recreación de la historia (Madison: Hispanic Seminary of Medieval Studies, 1994); "La prosa histórica de don Juan Manuel: la
} 
Saracino sobre las características del texto y de don Juan Manuel como autor de una "lectura desviada" de la Estoria de España, o el de Manuel Hijano Villegas sobre la relación de la Crónica abreviada con el arquetipo textual del que partiría, la Crónica Manuelina, y su evolución dentro de la historiografía post-alfonsí. ${ }^{9}$ También merece mención especial el hispanista Leonardo Funes, cuyas investigaciones establecen puntos de referencia sobre diferentes aspectos de don Juan Manuel y su obra, así como en la reconsideración de algunos aspectos de la historiografía post-alfonsí. ${ }^{10}$

En este trabajo nos planteamos como objetivo observar el estudio del texto y el autor hasta la fecha para aproximarnos a una comprensión histórico-cultural de su situación dentro de (y frente a) la cronística post-alfonsí de inicios del siglo XIV en la que se insertan. En primer lugar, observaremos el lugar que ocupa la Crónica abreviada dentro de la tradición manuscrita de la Estoria de España, tanto en lo textual como en lo ideológico. Para ello, partimos de los trabajos existentes sobre las relaciones entre don Juan Manuel y la cronística alfonsí y post-alfonsí. En segundo lugar, veremos cómo se configuran algunos de los relatos post-alfonsíes identificados por la crítica en el interior de la Crónica abreviada para ver cómo don Juan Manuel varía el discurso ideológico a través de su particular forma de escribir la historia. Hecho esto estaremos en condiciones de establecer algunas pautas que podrían guiar una mejor comprensión histórico-cultural de don Juan Manuel como cronista dentro de su contexto.

\section{La Crónica abreviada en las tendencias historiográficas derivadas de la Estoria de España}

Para estudiar el encaje de don Juan Manuel en la historiografía post-alfonsí a inicios del siglo XIV, es necesario comprender cómo se localiza su Crónica abreviada en la amplia y variada producción textual que derivó de la Estoria de España. Para ello comenzaremos observando la periodización y las dinámicas generales de la historiografía alfonsí y post-alfonsí en relación con la génesis de la Crónica abreviada. Acto seguido, prestaremos atención a la presencia de variaciones ideológicas en estas tendencias historiográficas de la Castilla medieval entre finales del siglo XIII e inicios

Crónica Abreviada y el Libro de las armas", en Actas del III Congreso de la Asociación Hispánica de Literatura Medieval, ed. M. Isabel Toro Pascua, vol. 1 (Salamanca: Universidad de Salamanca, 1994), 181-186; y "Género literario y técnicas narrativas de la Crónica Abreviada”, Crítica Hispánica 10, 1-2 (1988): 41-48.

${ }^{8}$ Pablo Enrique Saracino, 'La Crónica Abreviada de don Juan Manuel, una 'lectura desviada' de la Crónica Alfonsí”, Medievalia, 38 (2006): 1-10.

${ }^{9}$ Manuel Hijano Villegas, "Monumento inacabado: la Estoria de Espana de Alfonso VII a Fernando III", Cahiers d'études hispaniques médiévales 37, 1 (2014): 13-44; "Historia y poder simbólico en la obra de don Juan Manuel", Voz y Letrra 25, 1-2 (2014): 71-109; y "El manuscrito Egerton 289 de la British Library y la Crónica Manuelina", e-Spania, 25 (2016), http://e-spania.revues.org/26096 [consulta 10 diciembre, 2019].

${ }^{10}$ En lo que respecta de forma concreta a la Crónica abreviada destacamos: Leonardo Funes, "Un lector calificado de la Estoria de Espanna alfonsí: el testimonio de La Crónica Abreviada de don Juan Manuel”, en Studia Hispanica Medievalia II, eds. María A. Rosarossa y Rosa E. Penna (Argentina: Ergon 1992), 41-48; "Paradojas de la voluntad de autoría en la obra de Don Juan Manuel", en Actas del XIII Congreso de la Asociación Internacional de Hispanistas, eds. Florencio Sevilla y Carlos Alvar, vol. 1 (Madrid: Castalia, 2000), 126-133; y "Don Juan Manuel y la herencia alfonsí", en Actas VIII Congreso de la Asociación Hispánica de Literatura Medieval, eds. Margarita Freixas, Silvia Iriso Ariz, y Laura Fernández, vol. 1 (Santander: Consejería de Cultura-Asociación Hispánica de Literatura Medieval, 2000), 781-788. 
del XIV, con el fin de comprender la matriz del planteamiento político sobre el que don Juan Manuel compone su obra.

\section{La Crónica abreviada y la Crónica manuelina en la tradición manuscrita de la Estoria de España}

A pesar de haber sido una obra inacabada y en parte como resultado de ello, la Estoria de España de Alfonso X dio lugar a una de las más fructíferas transmisiones textuales de toda la Castilla medieval. En dicha transmisión podemos diferenciar dos etapas, como son la alfonsí y la post-alfonsí, así como dos tipos de producto textual, las versiones y las crónicas. La etapa alfonsí comprendería desde el inicio del proyecto de la Estoria de España hasta la muerte del rey Sabio en 1284, o hasta los años inmediatamente posteriores. En este momento surgieron tres versiones sucesivas a consecuencia de intentar perfeccionar y terminar el texto. La etapa post-alfonsí se iniciaría con la disolución del scriptorium de Alfonso X tras su muerte. Durante este periodo no se generan versiones, sino crónicas, textos ajenos al proyecto alfonsí que reutilizan los materiales legados por éste (ya sean versiones o borradores) para elaborar obras diferentes. ${ }^{11}$ Leonardo Funes ha situado el final de la etapa post-alfonsí en la composición de la Crónica abreviada en torno a $1325 .^{12}$

Dentro de las versiones alfonsíes se identifican tres, como son la Versión primitiva, anterior a 1271, la Versión enmendada después de 1274 y la Versión crítica entre 1282 y 1284 . Todas ellas parecen haber derivado de un "arquetipo regio" inicial que probablemente no hubiese contado con el total visto bueno de Alfonso $\mathrm{X} .{ }^{13} \mathrm{El}$ aprovechamiento de los materiales alfonsíes en la génesis de las crónicas post-alfonsíes fue heterogéneo, pudiendo limitarse a la utilización de versiones de la Estoria de España o borradores de las mismas, o incluyendo materiales de otras crónicas postalfonsíes. ${ }^{14}$ Entre estas obras se localizaría la Crónica abreviada. Cabe mencionar aquí un caso particular, algo más difícil de clasificar, que se relaciona textualmente con la Crónica abreviada, como es el de la conocida como la Versión amplificada de 1289. Se trata de un texto derivado directamente de la Estoria de España, pero cronológicamente post-alfonsí, que se habría elaborado en el entorno intelectual de la Catedral de Toledo bajo la tutela de Sancho IV y María de Molina. ${ }^{15}$ Frente a la opinión mayoritaria de la

\footnotetext{
${ }^{11}$ Juan Bautista Crespo, “La Estoria de España y las crónicas generales”, 110-112.

${ }^{12}$ Leonardo Funes, "Materia legendaria en el discurso historiográfico del siglo XIV: la fantasía y la configuración literaria de una verdad histórica", en Fantasía y literatura en la Edad Media, eds. Miguel Nicasio Salvador, Santiago López Ríos y Esther Borrego Gutiérrez (Madrid: Iberoamericana-Vervuert, 2004), 169 (163-178).

${ }^{13}$ Inés Fernández-Ordóñez, "La historiografía alfonsí y post-alfonsí en sus textos. Nuevo panorama": $122-123$

14 Juan Bautista Crespo, "La Estoria de España y las crónicas generales", 114-117. Dentro de la clasificación que realiza Bautista Crespo destacamos el hecho de que presenta una subcategoría dentro de las crónicas, como es la de "crónica secundaria". Éstas serían crónicas post-alfonsíes que no partes de una versión o borrador alfonsí, sino de otras crónicas. Sobre ello puede verse el aparatado correspondiente del referido trabajo entre las páginas 117 y 118.

${ }^{15}$ Leonardo Funes, "Las letras castellanas en tiempos de Fernando IV: esbozo de una historia literaria", en El texto infinito: tradición y reescritura en la Edad Media y el Renacimiento, ed. Cesc Esteve (Salamanca: Seminario de Estudios Medievales y Renacentistas-Sociedad de Estudios Medievales y Renacentistas, 2014), 534-535 (529-542).
} 
crítica, Bautista Crespo consideró que en base a sus características no debería catalogarse como una versión post-alfonsí, sino como una crónica. ${ }^{16}$

En el caso particular de don Juan Manuel, cuando inicia la redacción de la Crónica abreviada hacia 1320, afirma estar sintetizando un ejemplar finalizado de la Estoria de España que no se ha conservado ${ }^{17}$. La crítica ha dado por llamar a este texto la Crónica Manuelina, que sería un ejemplar de la Estoria de España finalizado en la etapa post-alfonsí y que podría haber sido propiedad del padre de don Juan Manuel. ${ }^{18}$ La Crónica manuelina se presentaría, así, como el arquetipo de una rama textual de la que se conservan, por ahora, otros dos testimonios a parte del de don Juan Manuel. Uno de ellos es el ms. Egerton 289 de la British Library, de cuyo contenido y características dio cuenta Brian Powell en $1906^{19}$ y que ha sido recientemente estudiado por Manuel Hijano. Este manuscrito es un códice facticio que contiene, entre otros, las partes tercera y cuarta de la Estoria de España que coinciden con el libro III de la Crónica abreviada. ${ }^{20}$ En segundo lugar estaría un manuscrito poco tratado por la crítica española, como sería el ms. Spanish 1 de la John Rylands Library de Manchester. Francisco Bautista ha identificado varios pasajes que lo relacionan con la Crónica manuelina, que habría servido como una de las bases principales para su composición. ${ }^{21}$

En base a la disposición textual que ofrece don Juan Manuel en tres libros, se ha especulado sobre la posibilidad de que la Crónica Manuelina también hubiese constado de tres partes que inicialmente habrían funcionado de forma autónoma. Mientras que los libro I y II de la Crónica abreviada siguen materiales alfonsíes, el libro III, que abarca desde el reinado de Fernando I hasta el de Fernando III, se presenta como un fragmento diferenciado en el que se relaboran e introducen materiales post-alfonsíes, emparentándose con textos como la Versión retóricamente amplificada de 1289, la Crónica de Castilla y la Crónica ocampiana. ${ }^{22}$ Ahora bien, esto no implica necesariamente que la Crónica manuelina siguiese la misma disposición. En su estudio sobre el ms. Spanish 1 de la John Rylands Librar, Francisco Bautista señaló algunas cuestiones que emparentan a este manuscrito con el ms. Egerton 289 pero que no están presentes en la Crónica abreviada. Entre ellas estaría el hecho de que ambos hablan de la apertura de un cuarto libro tras el reinado de Alfonso VI, que se iniciaría con la historia de su hija la reina doña Urraca y su esposo don Alfonso de Aragón. ${ }^{23}$ Atendiendo a esto, si bien la configuración del libro III de la Crónica abreviada es lo que diferencia como grupo a las crónicas de origen "manuelino", no deberíamos

\footnotetext{
${ }^{16}$ Juan Bautista Crespo, “La Estoria de España y las crónicas generales”, 119-120.

17 “(...) esto fizo él porque non tovo por aguisado de començar tal obra y tan complida como la del rey, su tío; antes sacó de la su obra complida una obra menor, (...)” en Don Juan Manuel, Obras completas, eds. Carlos Alvar y Sara Finci (Valencia: Proyecto Parnaseo, 2014), 68.

${ }^{18}$ Diego Catalán, "Don Juan Manuel ante el modelo alfonsí”, 36-38.

19 Brian Powell, "British Library MS Egerton 289 and Santa Casilda", en Homenaje a Pedro Sainz. Rodríguez, vol. 1 (Madrid: Fundación Universitaria Española, 1986), 3-14.

${ }^{20}$ Manuel Hijano Villegas, "El manuscrito Egerton 289 de la British Library y la Crónica manuelina", $e$ Spania, 25 (2016), http://journals.openedition.org/e-spania/26096 [10 diciembre, 2019].

${ }^{21}$ Se trataría de los fragmentos que comprenden los reinados de Fernando I, Sancho II y Alfonso VI, entre los folios 210r-359v, así como el reinado de Alfonso VIII hasta la batalla de Las Navas de Tolosa entre los folios 75r-410v. Véase: Francisco Bautista, "Juan Pineda, la Crónica Manuelina y la historiografía post-alfonsí”, Medievalia 19, 1 (2016): 10-15 (7-32).

${ }^{22}$ Sobre esto pueden verse, por ejemplo, las opiniones de Diego Catalán y, en seguimiento de éste, las de Inés Fernández-Ordóñez y Juan Bautista Crespo: Diego Catalán, "Don Juan Manuel ante el modelo alfonsí", 41-50; Inés Fernández-Ordóñez, "La historiografía alfonsí y post-alfonsí en sus textos. Nuevo panorama": 127; Juan Bautista Crespo, "La Estoria de España y las crónicas generales”, 130-131

${ }^{23}$ Francisco Bautista, “Juan Pineda, la Crónica Manuelina y la historiografía post-alfonsí”: 25-26.
} 
descartar la posibilidad de que la Crónica manuelina estuviese dividida en cuatro partes igual que la Estoria de España. De este modo, el aceptar que la agrupación de las partes tercera y cuarta en un sólo libro fuese obra de don Juan Manuel nos permitiría anticipar el grado de originalidad y relaboración al que habría sometido a su fuente.

\section{Variaciones ideológicas en la escritura de la historia desde Alfonso X a don Juan Manuel}

La propia evolución de la transmisión manuscrita de la Estoria de España a través de las versiones alfonsíes y de las crónicas posteriormente derivadas ha conllevado variaciones en los planteamientos político-ideológicos de los diferentes textos. Mientras las versiones alfonsíes son, por defecto, de inspiración y composición regia, dentro de la cronística post-alfonsí en la que se inserta don Juan Manuel podemos establecer, de forma tentativa, dos subcategorías como serían la cronística regia y la nobiliaria, generadas en un doble contexto político de oposición (el dinástico del poder regio y el ideológico de la nobleza). ${ }^{24}$ Hacemos notar aquí que la idea de la existencia de una cronística de corte nobiliario no parece gozar de una aceptación unánime dentro de la crítica contemporánea, por lo que serán necesarias algunas matizaciones. Antes de ello, presentaremos algunas cuestiones sobre las versiones alfonsíes.

Fernández-Ordóñez ha demostrado que bajo la coordinación de Alfonso X se llevaron a cabo varias redacciones sucesivas de la Estoria de España (la primitiva, la enmendada y la crítica) que varían en estilo, contenido y estructura. Las diferencias entre las versiones alfonsíes no implican un cambio ideológico del texto, sino que más bien reflejan la evolución de los planteamientos del rey Sabio en consonancia con los avatares políticos que atraviesa su reinado. ${ }^{25}$ Tal y como planteó Leonardo Funes, el conjunto de la prosa post-alfonsí se caracteriza por la reacción al legado de Alfonso X, estableciéndose formas diversas de reacción, desvío, rechazo y reformulación; dentro de lo que siguiendo la terminología propuesta por Fernando Gómez Redondo podemos denominar como el marco cultural "molinista". 26 Atendiendo a esto presentamos algunas de las consideraciones de Fernández-Ordóñez sobre la evolución de las versiones alfonsíes que pueden ayudar a comprender la deriva de la cronística postalfonsí.

\footnotetext{
${ }^{24}$ Esta distinción dentro de la cronística post-alfonsí se puede encontrar en el trabajo de Leonardo Funes: Leonardo Funes, "Materia legendaria”, 164 y 168.

${ }^{25}$ En este sentido, la autora establece una interesante relación entre la evolución de la producción historiográfica alfonsí y la jurídica que, a nuestro parecer, podría resultar determinante para comprender el devenir del conjunto de la textualidad alfonsí y pos-alfonsí entre finales del siglo XIII e inicios del XIV. Para esta relación entre los textos historiográficos y los jurídicos véase: Inés Fernández-Ordóñez, "Variaciones en el modelo historiográfico alfonsí en el siglo XIII", en La historia alfonsí: el modelo y sus destinos, ed. Geroges Martin, (Madrid: Casa Velázquez, 2000), 65-74 (41-74).

26 Véanse, respectivamente: Leonardo Funes, "Don Juan Manuel y la herencia alfonsí", 781-782; Fernando Gómez Redondo, "Doña María de Molina y el primer modelo cultural castellano", en El intercambio artístico entre los reinos hispanos y las cortes europeas en la Baja Edad Media, coords. María C. Cosmen y otros (León: Universidad de León, 2009), 29-46; "El molinismo: un sistema de pensamiento letrado (1284-1350)", en Estudios de literatura medieval: 25 años de la Asociación Hispánica de Literatura Medieval, coords. Antonia Martínez Pérez y Ana Luisa Baquero Escudero (Murcia: Universidad de Murcia, 2012), 45-81. Cabe mencionar aquí que las propuestas de ambos autores no son, en origen, del todo compatibles. Aquí, observamos el molinismo como un marco cultural amplio que da cabida a variaciones ideológica tanto regias como nobiliarias. Por su parte, Gómez Redondo parece circunscribirlo a la producción regia, hecho que ha sido empleado como argumento para contradecir la defensa realizada por Funes sobre la existencia de una cronística nobiliaria post-alfonsí.
} 
La redacción de la Versión primitiva sería la más fiel al que habría sido el arquetipo alfonsí. Al igual que sucede con todas las obras comprendidas dentro del proyecto político-cultural de Alfonso X, la Estoria de España se compuso conforme a un programa didáctico-político "cuyo punto principal era instruir en el respeto al señor natural, vicario de Dios en la tierra, a través del ejercicio de la razón”. ${ }^{27}$ Aquí, el príncipe o señor natural es el protagonista y centro de la acción histórica en la narración, la cual sólo cobra sentido dentro del espacio y el tiempo de su gobierno. ${ }^{28}$

En lo que respecta a los cambios operados en la Versión enmendada después de 1274, no se puede considerar que impliquen una variación del modelo historiográfico. Dicha variación sí que se nota en la Versión crítica, que muestra una radicalización de los planteamientos políticos de Alfonso X después de la revuelta encabezada por Sancho IV en su contra y que llevó a su deposición y exilio en Sevilla en 1282. Algunos aspectos que podemos destacar de esta versión son la acentuación de la exaltación de la monarquía, evitando reproducir imágenes negativas del poder que impliquen debilidad o deshonra, y la reafirmación de la soberanía absoluta de la autoridad regia sobre la idea del pacto con los órdenes sociales defendida por los partidarios de Sancho IV. ${ }^{29}$

En lo que respecta a la cronística post-alfonsí, el principal giro ideológico que se opera en la escritura de la historia es el cambio de la perspectiva pro-regia de Alfonso X por una más pro-nobiliaria. Dentro de la vertiente regia hemos situado la Versión retóricamente amplificada de 1289 y, con gran probabilidad, la Crónica manuelina. En la Versión retóricamente amplificada de 1289 se introdujeron glosas y amplificaciones retóricas incorporando fuentes tanto estrictamente históricas como legendarias, contrarias al modelo historiográfico alfonsí. De igual modo, se reorientó el sentido ideológico del texto para adaptarlo a la nueva coyuntura política. En la construcción de la narración histórica como un discurso político, la nobleza adquiere mayor protagonismo en el desarrollo de los acontecimientos, reflejando un planteamiento en el que el poder regio se sustenta sobre el pacto con los grandes señores de la Corona. ${ }^{30}$ Reproduce, así, un modelo político que, si bien funcionó para justificar la actuación de Sancho IV en contra de Alfonso X, ${ }^{31}$ habría de traer grandes problemas para el gobierno de Fernando IV, que hubo de enfrentar las imposiciones de los violentos nobles castellanos entre los que destacó don Juan Manuel. ${ }^{32}$

En lo tocante a la Crónica manuelina, su relación textual con la Versión retóricamente amplificada de 1289 nos lleva a respaldar la posibilidad defendida por Manuel Hijano de que se tratase también de una obra de "inspiración monárquica",

\footnotetext{
${ }^{27}$ Inés Fernández-Ordóñez, "Variaciones en el modelo historiográfico alfonsí en el siglo XIII", 43.

${ }^{28}$ Inés Fernández-Ordóñez, "Variaciones en el modelo historiográfico alfonsí en el siglo XIII", 43-48.

${ }^{29}$ Inés Fernández-Ordóñez, "Variaciones en el modelo historiográfico alfonsí en el siglo XIII", 48-50.

${ }^{30}$ Inés Fernández-Ordóñez, "Variaciones en el modelo historiográfico alfonsí en el siglo XIII", 61-65.

${ }^{31}$ Véase aquí la comprensión de Fernando Gómez Redondo de la Versión retóricamente amplificada de 1289 como un cambio de modelo historiográfico y como la plasmación del pensamiento político que encauzó la actuación de Sancho IV durante su reinado: Fernando Gómez Redondo, Historia de la prosa medieval castellana. I. La creación del discurso prosístico: el entramado cortesano (Madrid: Cátedra, 1998), 961-964.

${ }^{32}$ Sobre los avatares políticos de Fernando IV con la nobleza de su tiempo resulta ilustrativo el trabajo de César González Mínguez en el que sintetiza las líneas generales de otros trabajos suyos anteriores más extensos: César González Mínguez, "Fernando IV de Castilla (1295-1312) perfil de un reinado", Espacio, tiempo y forma, 17 (2004): 223-244.
} 
redactada en Toledo, puede que incluso en el mismo scriptorium. ${ }^{33}$ En el estado actual de la cuestión, no estamos en condiciones de poder afirmar con total certeza cuál habría sido la variación ideológica operada en la Crónica manuelina. Ahora bien, a través de ella sí que podemos relacionar de algún modo a don Juan Manuel con los planteamientos regios que, en principio, habría contenido.

En cuanto a la problemática de la existencia de una cronística nobiliaria, podemos destacar un trabajo reciente de Leonardo Funes en el que actualiza y reafirma algunos de sus planteamientos sobre esta hipótesis desarrollados en estudios anteriores. ${ }^{34}$ También Inés Fernández-Ordóñez defendió en 1993 la existencia de una historiografía nobiliaria en forma de narraciones particulares independientes de la obra alfonsí al hablar del "descubrimiento de obras historiográficas perdidas". 35

Entre la muerte de Alfonso X y los inicios del siglo XIV la nobleza castellana habría generado un tipo de relato histórico marcadamente caballeresco, en el que se da cabida a formas narrativas como la fazaña, la anécdota, la épica y la leyenda, además de poner por escrito relatos orales sobre grandes linajes castellanos. Estos productos nobiliarios se habrían insertado en las crónicas a través de formas inacabadas de la Estoria de España, reorientándola ideológicamente. ${ }^{36}$ Consideramos oportuno mencionar aquí que la presencia de algunos de estos motivos narrativos en la Crónica abreviada ya fue identificada en su momento por Benito-Vessels. ${ }^{37}$

Ahora bien, la existencia de una cronística nobiliaria no implica necesariamente que esta dibujase una imagen negativa de los reyes castellanos. Al contrario, se prefiguran imágenes positivas de la realeza, pero construidas desde los parámetros ideológicos pro-nobiliarios. En este sentido, Funes ha apuntado que "uno de los resultados de esta producción historiográfica nobiliaria sería la configuración de una suerte de "edad heroica" de la aristocracia, un tiempo en el que tanto sus privilegios y libertades como su relevancia política y militar habrían alcanzado el máximo reconocimiento; un tiempo localizado, principalmente, en los reinados de Alfonso VIII y Fernando III". 38

\footnotetext{
33 Aquí, Hijano llega a plantear la posibilidad "de que don Juan Manuel hubiese intervenido en la creación de la Crónica manuelina": Manuel Hijano Villegas, "Historia y poder": 77-78. Sobre la filiación regia de la Crónica manuelina se puede ver también: Manuel Hijano Villegas, "El manuscrito Egerton 289 ".

${ }^{34}$ Leonardo Funes, "Historiografía nobiliaria castellana del período post-alfonsí: Un objeto en debate", $L a$ corónica 43, 1 (2014): 5-38. De igual modo, aunque con menor profundidad, se puede ver también: Leonardo Funes, "Historiografía nobiliaria del período post-alfonsí: un fenómeno histórico-literario en discusión”, en Hispanismos del mundo. Diálogos y debates en (y desde) el sur, coord. Leonardo Funes (Buenos Aires: Miño y Dávila, 2016), 77-86.

35 Inés Fernández-Ordóñez, "La historiografía alfonsí y post-alfonsí en sus textos. Nuevo panorama": 128-131. Cabe destacar que tano en la base de los planteamientos de Fernández-Ordóñez como los de Funes se puede identificar, con diferentes grados de aceptación, la tesis de Diego Catalán sobre la existencia de una hipotética Historia nobiliaria de Castilla que habría proveído interpolaciones en la transmisión manuscrita de la Estoria de España.

${ }^{36}$ Sobre esto destacamos los trabajos de Funes sobre la inclusión de elementos fantásticos en la cronística post-alfonsí, así como la consideración de Manuel Hijano sobre el modo en que se generan identidades aristocráticas que desarrollan sus propias historias familiares dentro del marco del enfrentamiento de la nobleza y la realeza castellanas. Véanse, respectivamente: Leonardo Funes, "Materia legendaria", 169; y Manuel Hijano Villegas, "Historia y poder": 101.

${ }^{37}$ Carmen Benito-Vessels, Juan Manuel: escritura y recreación de la historia, 47-86.

${ }^{38}$ Leonardo Funes, "Historiografía nobiliaria castellana": 24-27.
} 
Las historias de corte nobiliario se desarrollaron en gran medida a través de relatos particulares sobre pasajes y episodios de la historia reciente de Castilla a partir de Fernando I. En el libro III de la Crónica abreviada, que es la parte menos alfonsí del texto, se incluyen algunos de estos relatos, localizados en las narraciones sobre la historia del Cid dentro del reinado de Alfonso VI, sobre la minoría de edad de Alfonso VIII (en lo que se ha denominado como la Historia menos atajante) y sobre la actuación de los nobles don Lorenzo y Garcí Pérez en el reinado de Fernando III. ${ }^{39}$ Así, la figura de don Juan Manuel como cronista se ha asociado a la de un escritor de ideología señorial, representando un punto culminante del desarrollo preexistente de una tendencia historiográfica nobiliaria castellana ajena a los planteamientos regios. ${ }^{40}$

Entre los productos textuales de esta cronística nobiliaria habría que incluir también la aparición de una leyenda negra sobre Alfonso X, conocida como La leyenda de la blasfemia del Rey Sabio, cuyo origen se remonta al conflicto sucesorio entre Alfonso X y Sancho IV. ${ }^{41}$ Este relato, eminentemente oral, "condensó el juicio de sus contemporáneos sobre la figura de Alfonso $\mathrm{X}$ y proporcionó a las generaciones siguientes una explicación trascendental de los difíciles y turbulentos tiempos que se prolongaron por más de medio siglo después de la caída del Rey Sabio", siendo El libro de las tres razones de don Juan Manuel (junto con la Crónica de 1344) una de sus primeras manifestaciones escritas. ${ }^{42}$

\section{Lo particular de la Crónica abreviada y sus variaciones sobre el relato historiográfico post-alfonsí}

Hasta aquí, la localización de la Crónica abreviada dentro de la tradición manuscrita de la Estoria de España nos ha permitido observar una posición ambigua de don Juan Manuel entre los modelos de la cronística post-alfonsí, relacionándose a la vez con la vertiente regia (en lo textual principalmente) y con la nobiliaria (en la composición ideológica del relato). Se trata de una localización poco clara, seguramente debido a la compleja perspectiva ideológica que deriva de su situación personal como hijo de infante, a medio camino entre la familia real y los ricohombres. ${ }^{43}$ Sobre esta base observaremos la forma en que don Juan Manuel varía su relato, desmarcándose un tanto de las tendencias historiográficas del momento para generar un discurso histórico que se adapte a sus necesidades e intereses particulares.

\footnotetext{
${ }^{39}$ Sobre esto puede verse principalmente: Diego Catalán, "Don Juan Manuel ante el modelo alfonsí”, 4350. De igual modo: Leonardo Funes, "Historiografía nobiliaria castellana", 20-23. Sobre la localización de estos relatos en el Crónica manuelina se pueden ver: Francisco Bautista, "Juan Pineda, la Crónica Manuelina y la historiografía post-alfonsí": 24; y Manuel Hijano Villegas, "El manuscrito Egerton 289".

${ }^{40}$ Leonardo Funes, "Historiografía nobiliaria del período post-alfonsí', 84.

${ }^{41}$ Leonardo Funes, "Materia legendaria", 169.

${ }^{42}$ Uno de los principales investigadores sobre esta cuestión ha sido Leonardo Funes, de quien se puede destacar un trabajo publicado en dos partes entre 1993 y 1994: Leonardo Funes, "La blasfemia del Rey Sabio itinerario narrativo de una leyenda (I)", Incipit, 13 (1993): 51-70; "La blasfemia del rey Sabio itinerario narrativo de una leyenda (II)", Incipit, 14 (1994): 69-101. Más recientemente ha publicado una revisión actualizada de estos planteamientos en: Leonardo Funes, "La leyenda de la blasfemia del Rey Sabio: revisión de su itinerario narrativo", e-Spania (2016), http://journals.openedition.org/espania/25873 [11 diciembre, 2019].

${ }^{43}$ Sobre esto, Salvador Moxó apuntó como los hijos de infante difícilmente se asociaban al grupo social constituido por el rey y su familia (los infantes), incluyéndose más bien entre los ricohombres como sector más elevado de la nobleza: Salvador Moxó, "La nobleza castellana en el siglo XIV”, en Clásicos De Historia Social De España: Una Selección Crítica, comps. P. Sánchez León y J. Izquierdo (Valencia: Centro Francisco Tomás y Valiente-Fundación Instituto Historia Social, 2000), 96 (87-116).
} 
De entrada, a nuestra intención podría objetarse que gran parte de la argumentación de la Crónica abreviada podría aplicarse de forma general a la Crónica manuelina. Ahora bien, hemos de considerar que, en el estado actual de la materia, la mayoría de las hipótesis sobre la Crónica manuelina parten casi unilateralmente del testimonio de la Crónica abreviada que, a su vez, presenta algunas diferencias propias con respecto los otros testimonios "manuelinos".

Suscribiendo una de las observaciones finales de Fernández-Ordóñez en su estudio sobre "la historiografía alfonsí y post-alfonsí en sus textos", notamos que son las variantes particulares que ofrece cada obra las que permiten comprender la peculiaridad de la misma e interpretarla de forma correcta. ${ }^{44}$ Tal y como se ha venido indicando, el libro III de la Crónica abreviada es el elemento más representativo del texto. Se ha dicho, también, que la historiografía post-alfonsí se desarrolla a través de historias nobiliarias con tintes épicos y ficticios. Así, veremos cómo don Juan Manuel altera algunos relatos contenidos en la Historia del Cid, la Historia menos atajante y en la historia concerniente al reinado de Fernando III. De igual modo, destaca la forma en que, en pleno florecimiento de la leyenda negra de Alfonso X, presenta una imagen positiva de éste en el prólogo de la Crónica abreviada y evita su denostación al mencionarlo en la muerte de Fernando III.

Puntualizamos aquí que la labor que seguidamente se acomete no es la comparativa textual entre la Crónica abreviada y el corpus de crónicas post-alfonsíes, la cual excedería con mucho la pretensión de este trabajo. En su lugar, hemos contrastado las consideraciones de otros autores como Benito-Vessels, Diego Catalán o Manuel Hijano a tal efecto. Entre ellos, consideramos oportuno recuperar la defensa de BenitoVessels sobre la originalidad de la Crónica abreviada en base al proceso de selección y síntesis literaria realizada, ${ }^{45}$ contrastando con otras perspectivas historiográficas más recientes que consideran la Crónica abreviada como poco más que un índice de la Estoria de España elaborado por don Juan Manuel bajo la creencia de que sumariaba la obra original de su tío Alfonso X. ${ }^{46}$

\section{Los relatos nobiliarios desde la perspectiva de don Juan Manuel}

Tanto los temas como los personajes tratados en el libro III de la Crónica abreviada forman parte de un discurso cronístico eminentemente nobiliario y desarrollado bajo el prisma de la literatura épica. Por ello, conviene que nos paremos en las alteraciones que sobre estos introduce don Juan Manuel para ver la forma en que reorienta conscientemente su sentido. En lo que sigue trataremos tres casos: a) el relato de Alvar Fáñez; b) la Historia menos atajante; y c) el episodio de Garcí Pérez y don Lorenzo durante el reinado de Fernando III.

\footnotetext{
44 Inés Fernández-Ordóñez, "La historiografía alfonsí y post-alfonsí en sus textos. Nuevo panorama": 132.

${ }^{45}$ Benito-Vessles, Escritura y recreación, 22.

${ }^{46}$ Se trata esta de una comprensión decimonónica que podemos encontrar en Pascual Gayangos, quien definió el texto de la Crónica abreviada (mal identifico como una hipotética Crónica complida) como un compendio de la Crónica General: Pascual Gayangos, Escritores en prosa anteriores al XIV (Madrid: Biblioteca de Autores Españoles, 1860), xxi. La misma idea parece haber persistido entre algunos críticos actuales, como sería el caso de Juan Bautista Crespo en su trabajo sobre "La Estoria de España y las crónicas generales" del año 2000: Juan Bautista Crespo, "La Estoria de España y las crónicas generales", 130-131.
} 
a) El relato de Alvar Fáñez. Alvar Fáñez es un personaje destacado dentro de la historia del Cid, en el reinado de Alfonso VI, altamente mencionado en la cronística post-alfonsí. Entre las principales características de este caballero destacan la fidelidad a su señor y sus buenas capacidades diplomáticas y militares. En la Crónica abreviada se lo menciona en unos doce capítulos, en los que aparece siempre al servicio de otros, principalmente de Alfonso VI o del Cid. Aunque cumpliendo con su servicio obtuvo importantes logros, don Juan Manuel los menciona de forma neutral desproveyéndolo de su halo heroico. Si bien sus hazañas serían de sobra conocidas, las omisiones de la Crónica abreviada parecen componer un recurso discursivo que condena el excesivo servilismo del personaje como rasgo nobiliario negativo. Cabe notar que se trata de una actitud que también caracteriza al Cid, siempre esforzándose por ganar el favor del rey a pesar de las ofensas recibidas. Si bien es cierto que las virtudes atribuidas al modelo heroico del Cid fueron variando entre los siglos XIII y XIV,${ }^{47}$ la crítica abierta por parte de don Juan Manuel hacia este personaje habría resultado casi sacrílega. En este sentido, parece plausible la explicación de Benito-Vessels sobre el recurso a la sátira indirecta a través de su caballero Alvar Fáñez. ${ }^{48}$

b) La Historia menos atajante. La Historia menos atajante es una versión nobiliaria alternativa sobre el relato de la minoría de Alfonso VIII según el cual éste habría recuperado y mantenido el reino gracias al apoyo de sus nobles. En la interpretación ideológica de este pasaje podemos encontrar opiniones confrontadas. Por un lado, Diego Catalán observó que el protagonismo de la nobleza sería un rasgo pronobiliario en oposición al monarquismo de la historiografía alfonsí. ${ }^{49}$ Por el otro, tendríamos consideraciones como la de Manuel Hijano que, notando que el relato en la Crónica abreviada sirve de marco narrativo para desarrollar ideas políticas como la relación de fidelidad y vasallaje entre la nobleza y la realeza, ${ }^{50}$ ha hecho notar que la redacción en los textos manuelinos (así como en la Versión amplificada de 1289) se ajustaría más bien a la perspectiva regia, mostrando una nobleza sometida mediante vínculos de fidelidad. ${ }^{51}$ Atendiendo a lo expuesto hasta aquí y contextualizando estas afirmaciones en la actividad política y militar desplegada por don Juan Manuel, no parece que el sometimiento sea un elemento característico de su pensamiento político. Ahora bien, esto no implica necesariamente un posicionamiento absoluto a favor de la perspectiva nobiliaria por parte de un autor que se esfuerza en presentarse como miembro de la familia real. ${ }^{52}$

Llamamos aquí la atención sobre una lectura de la Crónica abreviada contrastada por Diego Catalán con la Crónica ocampiana para reconstruir el relato de la Historia menos atajante y que ha llamado nuestra atención por cuanto sirve para ejemplificar los planteamientos "juanmanuelinos" contra el servilismo excesivo. Se trata del final del capítulo CCII, en el que el conde don Lope se despide de Alfonso VIII tras ayudarle en una batalla. El suceso se narra con gran brevedad, finalizando con una alusión al

\footnotetext{
${ }^{47}$ David G. Pattison, "El Mío Cid del poema y el de las crónicas: evolución de un héroe", en El Cid: de la materia épica a las crónicas caballerescas, eds. Carlos Alvar y otros (Sevilla: Universidad de Alcalá, 2002), 23-27.

${ }^{48}$ Benito-Vessles, Escritura y recreación, 105.

${ }^{49}$ Diego Catalán, "Don Juan Manuel ante el modelo alfonsí", 43-46.

${ }^{50}$ Hijano, "Historia y poder": 75.

${ }^{51}$ Manuel Hijano Villegas, "Fuentes romances de las crónicas generales: el testimonio de la Historia menos atajante", Hispanic Research Journal 12, 2 (2011): 129-131.

52 Baste aquí referirnos a la presentación a la fórmula "yo, don Johan, fijo del infante don Manuel" con la que se presenta a sí mismo en sus escritos, insistiendo en su pertenencia al linaje real.
} 
reconocimiento de su servicio por parte de Alfonso VIII. La neutralidad de este pasaje contrasta con el mismo contenido en la Crónica ocampiana, donde se muestra a un don Lope absolutamente servil y obediente.

Crónica abreviada, libro III, capítulo Crónica Ocampiana CCII.

"(...) y dize cómo el rey Lope, de Denia, y el conde Lope, de Nájara, vinieron allí con grandes gentes en ayuda del rey. (...) Otrossí dize qu'el rey de Denia y el conde don Lope despidiéronse del rey y fuéronse para sus casas muy pagados del rey don Alfonso". 53
"El conde don Lope, que veniera a esta çerca en ayuda del rey commo ya dicho avemos, (...) e otrosy despedyose del rrey, e prometyole su serviçio e su ayuda para quando menester ovise (...). E otrosy el conde don Lope, que veno a esta çerca commo ya desuso oystes, con grand voluntad que avia de servir al rey se despydio del para se yr a su tierra $(\ldots),{ }^{54}$

c) El episodio de Garcí Pérez y don Lorenzo durante el reinado de Fernando III. En la parte correspondiente al reinado de Fernando III, la alteración que don Juan Manuel introduce en el relato sobre los caballeros Garcí Pérez y don Lorenzo llama la atención por su sintetismo y neutralidad. En la historia se narra cómo los musulmanes merman las tropas de Fernando III lanzando ataques periódicos hasta que un caballero, don Lorenzo, propone contraatacar en un puente del río Guadaíra. En su plan se prohíbe explícitamente llegar hasta dicho puente para evitar riesgos, pero él mismo se adentra hasta la mitad. En este punto es imitado por el caballero Garcí Pérez Vargas que, desobedeciendo una orden directa, estimula con su ejemplo al resto de la tropa y logran una gran victoria.

Tal y como se presenta el acontecimiento, la victoria no se obtiene gracias a don Lorenzo, cuya actitud puede resultar cuestionable, sino gracias a la insumisión de Garcí Pérez, convertido en modelo de virtud caballeresca. Tal y como apuntó Benito-Vessels, don Juan Manuel elimina la finalidad moral del relato, presentando la victoria como consecuencia de una estrategia pactada por los dos caballeros, cuya única virtud destacada es el valor. ${ }^{55}$ Esta alteración parece buscar la prefiguración de imágenes caballerescas positivas, eliminando contravalores como la desconfianza de don Lorenzo o la desobediencia de Garcí Pérez.

\begin{tabular}{|l|l|}
\hline $\begin{array}{l}\text { Crónica abreviada, libro III, capítulo } \\
\text { CCCXXVII. }\end{array}$ & Primera Crónica General, capítulo 1170. \\
\hline "Y don Llorenço Suárez fabló con & "Quando don Llorenço Suárez sopo \\
Garci Pérez de Vargas y con los otros & el danno que fazien los moros (...)dixo a \\
cavalleros que ý estavan cómo fiziesen & Garçi Perz de Vargas et a otros cavalleros \\
una espolonada en los moros, mas que & que y estavan con el: fagamos vna \\
non pasasen la ponteziella, ca estavan & espolonada en los aquellos moros (...), \\
\hline
\end{tabular}

\footnotetext{
${ }^{53}$ Don Juan Manuel, Obras completas, 188.

${ }^{54}$ El fragmento aparece recogido por Diego Catalán en: Diego Catalán, "Don Juan Manuel ante el modelo alfonsí”, 44-45.

${ }^{55}$ Carmen Benito-Vessels, Juan Manuel: escritura y recreación, 95-97
} 
allende la puente bien $\mathrm{X}$ mill moros; $\mathrm{y}$ ellos fizieron su espolonada y vencieron a los moros. Y llegó don Llorencio Xuárez fasta medio la puente $\mathrm{y}$, en tornándose, paró mientes y vio allende de la puente a Garci Pérez, que estava con los moros, y avié ya derribado bien cuatro d'ellos; y luego tornose don Llorencio Suárez con los cavalleros que ý estavan con él y pasaron la puente y ovieron su pelea con los moros muy brava, pero al cabo vencieron a los moros (...)". ${ }^{56}$ mas catad commo ninguno de nos non entre en la puente nin llegue a ella, que seer nos ye grant peligro (...); et esto dizie don Lorenço por provar a Garçi Perez de Vargas que seria lo que y farie. (...) Et veniendose, paro mientes por Garçi Perz Vargas, et nol vio; et torno la cabeça et cio que evie pasado la puente (...). >Cavalleros-dixo don Lorenço Suarez- engannados nos a Garçi Perez. Vedes commo a pasada la pontezilla el; mas faranos oy entrar en tallogar que avremos todos mester el ayudorio de Dios. et porque me reçelava yo del, ove yo dicho que ninguno non entrase en la pontezilla. Pues asy es, et nol podemos enden tornar, vayamosle acorrer, que esto a fazer es; ca en otra guisa, mal nos estaria, sy a tan buen cavallero commo es Garçi Pérez, se oy perdiese por la nuestra mengua". 57

\section{EI "no relato" sobre Alfonso X}

Un elemento que es necesario destacar de la Crónica abreviada con relación a la cronística post-alfonsí es el uso que don Juan Manuel hace de la figura de su tío Alfonso $X$. Si bien apenas se lo menciona en la narración porque esta termina con la muerte de Fernando III, se lo elogia profusamente en el prólogo como político e intelectual, dando una imagen abiertamente contraria a la sostenida en el ambiente político de inicios del siglo XIV con la difusión de la Leyenda de la blasfemia del rey Sabio. En base a esto, podemos hablar de un "no relato" que mostraría de forma casi pura la opinión de don Juan Manuel sobre su tío a través de los elogios en el prólogo y la omisión en el cuerpo del texto.

La leyenda de Alfonso X se configura como un relato legendario sobre una matriz pecado-castigo que condena la actividad intelectual del rey Sabio desde una doble perspectiva. Por un lado, la religiosa, considerando que el saber lleva a la soberbia y, por el otro, la ideológica, observando que el ejercicio de las letras es incompatible con el ejercicio eficiente de las armas y el gobierno. Se generó así un relato que explica el trágico final de Alfonso X y la penosa situación de Castilla en aquel momento, condenándolo moralmente y justificando la oposición a su autoridad. ${ }^{58}$

Al cesar la narración de la Crónica abreviada en la muerte de Fernando III, Alfonso $\mathrm{X}$ sólo es mencionado como receptor de las últimas palabras de su padre moribundo entre los capítulos CCCXL y CCCXLI. En caso de haber querido introducir una evaluación negativa de su tío, éste habría sido el lugar. Sin embargo, el tratamiento que se da a Alfonso X parece neutral. Tenemos, pues, que lo destacable aquí es la

\footnotetext{
${ }^{56}$ Don Juan Manuel, Obras completas, 208.

57 Alfonso X, Primera crónica general de España: que mandó componer Alfonso el Sabio y se continuaba bajo Sancho IV en 1289, ed. Ramón Menéndez Pidal (Madrid: Gredos, 1955), 760.

${ }^{58}$ Leonardo Funes, "Materia legendaria”, 171.
} 
ausencia del relato. Se podría considerar que lo más parecido a la reproducción de los valores ideológicos de la nobleza como opositora a los intentos de fortalecimiento del poder regio en este pasaje, es una lectura del capítulo CCCXL en que Fernando III ordena a Alfonso $\mathrm{X}$, en tanto que su heredero, que guarde y respete los fueros $\mathrm{y}$ privilegios de la nobleza: "y rogol cuanto pudo (...) por todos los ricos omnes y cavalleros de sus regnos, que les fiziese mucha onra y los mantoviese y les feziese algo, en guisa que podiessen muy bien pasar, y que les guardase sus fueros y sus libertades a ellos y a todos sus pueblos. Y díxol que si esto ansí feziese, quel dava la su bendición, y si non, quel dava su maldición". Si bien la actuación de Alfonso X fue contraria a estos postulados, especialmente en lo que respecta a su intento de imposición sobre la nobleza a través de sus textos jurídicos, y siendo don Juan Manuel consciente de ello, en la Crónica abreviada la crítica nobiliaria post-alfonsí se neutraliza cambiándola por una mera advertencia.

Esta acción se puede entender atendiendo al contra-relato que don Juan Manuel desarrolla en el prólogo del texto exaltando las virtudes de Alfonso X como gobernante culto. En esto parte de un elogio intelectual para afirmar que su gran entendimiento, que procede de la gracia divina y no de la soberbia personal, se orientó siempre al beneficio del reino y al servicio de Dios: “(...) lo uno, por el muy grant entendimiento que Dios le dio; lo ál, por el grant talante que avié de fazer nobles cosas y aprovechosas; lo ál, que avía en su corte muchos maestros de las ciencias y de los saberes a los cuales él fazía mucho bien, y por levar adelante el saber y por noblecer sus regnos. (...)Y este muy noble rey don Alfonso, entre muchas nobles cosas que fizo, ordenó muy complidamente la Crónica d'España, y en las crónicas que él compuso y mandó componer, que avía muy grant entendimiento y avía muy grant talante de acrecentar el saber, y cobdiciava mucho la onra de sus regnos y que era alumbrado de la gracia de Dios para entender y fazer mucho bien. Mas por los pecados de España y por la su ocasión y señaladamiente de los que estonce eran, y aun agora son, del su linage, ovo tal postrimería que es quebranto de lo dezir y de lo contar. Y siguiosse ende tal daño que dura agora y durara cuanto fuere voluntat de Dios". ${ }^{59}$ Contradice, así, las dos líneas argumentales sobre las que se desarrolla la leyenda negra y, además, mantiene la idea del pecado como causante de la desgracia del reino, pero se presenta como un mal atribuido al reino en lugar de al rey Sabio, limpiando con ello su imagen.

Sobre la vinculación de don Juan Manuel con la imagen que proyecta de Alfonso $X$, la crítica ha aceptado la idea de que recurre a un tipo de emulación sobre la que habría construido su autoconciencia autoral. ${ }^{60}$ Aceptando esta hipótesis, ha de observarse que la identificación como un noble e intelectual supondría "un flagrante desvío de sus deberes estamentales". ${ }^{61}$ Autores como Saracino e Hijano han hecho hincapié en cierta connotación política de esta adulación y emulación de Alfonso X, de lo que se comprende un tipo de auto-exaltación como autor diferenciado y como

\footnotetext{
${ }^{59}$ Don Juan Manuel, Obras completas, 46-74.

${ }^{60}$ Entre los primeros estudiosos en tratar este tema podemos encontrar a Diego Catalán y a Germán Orduna, cuyos patentamientos fueron aceptados por autores posteriores como María Jesús Lacarra. Véase: Germán Orduna, "Los prólogos a la Crónica Abreviada y al Libro de la Caza": 132, 134 y 139140; Diego Catalán, "Don Juan Manuel ante el modelo alfonsí,", 228-229; y María Jesús Lacarra, "Don Juan Manuel (1282-1348): orgullo nobiliario y escritura", en Don Juan Manuel y su producción literaria, coord. María Jesús Lacarra (Valencia: Proyecto Parnaseo, 2014), 12 (5-15).

61 Leonardo Funes, "Excentricidad y descentramiento en la figura autoral de don Juan Manuel", eHumanista, 9 (2007): 11 (1-19).
} 
miembro de la familia real. ${ }^{62}$ Este tipo de afirmaciones bastarían, en principio, para observar el confuso anclaje de don Juan Manuel entre los cronistas nobiliarios postalfonsíes. No obstante, ha de tenerse en cuenta también la concepción del saber como un elemento con utilidad sociopolítica que permite el engrandecimiento del reino. Atendiendo a los planteamientos de Manuel Alvar en $1996,{ }^{63}$ podemos afirmar que lo que se elogia no es, en sí, la imagen del intelectual, sino un modelo de conducta en el que lo político y lo cultural son elementos indisociables.

\section{Don Juan Manuel como cronista ante la historiografía post-alfonsí}

Hasta aquí hemos visto el lugar que ocupa la Crónica abreviada en la tradición textual de la Estoria de España y cuáles son los elementos ideológicos que caracterizan su narración frente al grueso de la cronística post-alfonsí. Poniendo estos elementos en conjunto, podremos analizar la realidad de don Juan Manuel como historiador frente a la historiografía de su tiempo. Para ello, trataremos dos cuestiones. Primero, la caracterización de don Juan Manuel como autor de una crónica, atendiendo a la existencia de un planteamiento particular y a la formación de un estilo narrativo específico. Segundo, a la diferenciación ideológica que muestra como autor y como político frente al resto de la cronística castellana de inicios del siglo XIV.

Cuando don Juan Manuel inicia su labor de escritura ya tiene una concepción madura de la prosa. $^{64}$ A nivel autoral destaca por poseer un estilo diferenciado, desarrollado de forma consciente y que contrasta con el total anonimato de la cronística post-alfonsí. Su narrativa es directa, sutil y sencilla ${ }^{65}$, lo que concuerda con el propósito que declara en el prólogo de la Crónica abreviada: resumir un texto demasiado amplio para hacerlo más manejable.

Si la encuadramos dentro de la historiografía post-alfonsí, lo que primero llama la atención de la Crónica abreviada es, precisamente, el planteamiento declarado por el autor. Don Juan Manuel no reutiliza el material alfonsí para redactar una crónica nueva, sino que resume la Estoria de España, presentándose a sí mismo como continuador de la labor cultural de su tío. ${ }^{66}$ De este modo, se desmarca de sus contemporáneos y se sitúa, tentativamente, más cerca de las versiones alfonsíes que de las crónicas posteriores.

El método de resumen empleado es uno de los rasgos que configurarían lo que Benito-Vessels denominó como el ars historiandi de don Juan Manuel. ${ }^{67}$ Ahora bien, analizando el sentido en el que funciona, el desarrollo de un estilo propio parece tener

\footnotetext{
${ }^{62}$ Pablo Enrique Saracino, "La Crónica Abreviada de don Juan Manuel”: 1-10; y Manuel Hijano Villegas, "Historia y poder": 83-84.

${ }^{63}$ Manuel Alvar, "Alfonso X contemplado por don Juan Manuel", en Actas del Congreso Internacional La literatura en época de Sancho IV”, eds. Carlos Alvar y José Manuel Lucía Megías (Alcalá: Universidad de Alcalá, 1996), 91-106.

${ }^{64}$ Diego Catalán, "Don Juan Manuel ante el modelo alfonsí”, 27.

${ }^{65}$ Sobre esto hay coincidencia general de opiniones, tanto a nivel cronístico como artístico. Sobre ello véase: Diego Catalán, "Don Juan Manuel ante el modelo alfonsí”, 27-28; y Carmen Benito-Vessels, Juan Manuel: escritura y recreación, 80-86.

${ }^{66}$ Pablo Enrique Saracino, "La Crónica Abreviada": 7-8.

${ }^{67}$ Carmen Benito-Vessels, Juan Manuel: escritura y recreación, 39.
} 
un sentido político funcional, que le permite alterar el contenido del texto camuflando su criterio personal a través de recursos discursivos como la omisión o el desplazamiento de la atención sobre algún tema. ${ }^{68}$

Analizando lo expuesto hasta aquí, podemos afirmar que la posición de don Juan Manuel como historiador es, cuanto menos, ambigua. Se diferencia de la historiografía post-alfonsí en su planteamiento, pero incluye características formales e ideológicas propias de los relatos nobiliarios. En este sentido, la catalogación de don Juan Manuel como noble rebelde y levantisco podría condicionar la comprensión de la obra como ejemplo de crónica post-alfonsí nobiliaria. No obstante, analizando el relato se ve que no muestra una filiación ideológica clara y que se pueden apreciar posiciones, si no favorables, al menos no del todo críticas hacia la Casa Real, como sucedería con la adaptación de la Historia menos atajante. A esto podríamos sumar la no condena de Alfonso X al final de la obra y su exaltación en el prólogo. En este sentido, parecería ilógico que se insertase a sí mismo como continuador de un proyecto político-cultural que, como autor estrictamente nobiliario, se centraría en denostar.

Por otra parte, la posición favorable de don Juan Manuel respecto a determinados aspectos de la autoridad regia contrasta con su condena reiterada del servilismo como contravalor nobiliario. Parece partidario de un tipo de nobleza fuerte y con autonomía, propia de la época de Fernando IV en la que vivió. Ahora bien, esto no significa que sea partidario de la rebeldía y la desobediencia, por lo que neutraliza el relato de Garcí Pérez y don Lorenzo.

Visto esto, resulta complicado definir a don Juan Manuel como cronista porque muestra trazas de un fuerte individualismo y de una personalidad política diferenciada. Frente a opiniones generalizadas sobre su calidad de representante de la corriente historiográfica post-alfonsí nobiliaria, vemos que en algunos puntos se diferencia de ella y se aproxima a una perspectiva regia cercana a la de Sancho IV con la Versión amplificada de 1289, pero sin incurrir en la denostación de la figura de Alfonso X. Es posible que esta particularidad historiográfica se deba, por un lado, a su ambigua posición social como hijo de infante y, por el otro, a la particularidad de su persona como noble con preocupaciones político-culturales. Así, en este punto no podemos menos que suscribir la opinión de Leonardo Funes en su definición de don Juan Manuel como un autor excéntrico. ${ }^{69}$

\section{Conclusión}

A la hora de observar el anclaje de la Crónica abreviada dentro de la historiografía post-alfonsí, vemos que destaca por varias peculiaridades dada la ambigüedad de su posicionamiento. Si bien parece emparentarse con la cronística postalfonsí regia a través de su arquetipo, la Crónica manuelina, las peculiaridades de algunos de los relatos internos que conforman la narración la relacionan con la producción textual de corte nobiliario. En un aspecto estrictamente textual, llama también la atención el modo en que la obra se presenta como una continuación directa de la Estoria de España y no como una crónica diferente. Este aspecto revela también una intención expresa de don Juan Manuel de vincularse a la producción regia.

\footnotetext{
${ }^{68}$ Sobre la variación ideológica del significado a través de diferentes técnicas discursivas puede verse: Teun A. van Dijk, Ideología y discurso (Barcelona: Ariel, 2003), 58-65.

${ }^{69}$ Leonardo Funes, "Excentricidad y descentramiento": 1-19.
} 
$\mathrm{Si}$ atendemos al desarrollo de la narración en el libro III como parte más representativa del texto, la sutil variación de los relatos, principalmente a través del recurso a la abreviación, lo ubica en una situación que, si bien no es antinobiliaria, tampoco se opone de forma directa al poder regio. En este sentido, la ambigüedad es también un rasgo destacado de don Juan Manuel como historiador. Así, lo que aparentemente se podría entender como indeterminación ideológica, parece relacionarse con la formación de una autoconciencia social y autoral sólida. Esta localización entre ambas tendencias (regia y nobiliaria) se explica observando que la perspectiva ideológica adoptada no es la de un grupo u otro. Más bien responde a un punto de equilibrio entre ambas que refleja de forma directa a los planteamientos, intereses y necesidades personales de don Juan Manuel como hijo de infante dentro de un contexto determinado.

Acaso se podría considerar, con cierta precaución, que la Crónica abreviada se inserta en una línea historiográfica propia (la personal de don Juan Manuel). Un modelo de historia que, en el periodo post-alfonsí, se acerca tentativamente al de Alfonso X para mostrar una visión particular y personal de la realidad política de Castilla a inicios del siglo XIV. El establecimiento de categorías y divisiones dentro de la complejísima historiografía alfonsí y post-alfonsí no debería constituir un esquema dentro del cual localizar nuestro texto. Más bien compone una de tantas dimensiones contextuales en las que se mezclan lo político, lo social y lo cultural (textual), y en base a las cuales ha de ser comprendida e interpretada la escritura "juanmanuelina".

Por último, resulta de gran interés observar la peculiaridad de la Crónica abreviada dentro de la cronística post-alfonsí en relación al tratamiento dispensado hacia Alfonso X. Varios han sido los autores que acertadamente han estudiado aspectos como la formación de una conciencia autoral germinada sobre la imagen del rey Sabio, o las implicaciones de autoexaltación política que esto conllevaría. Junto con todo ello, lo que nos parece importante resaltar aquí es el aspecto, menos tratado, de la comprensión unitaria de la política y la cultura. Esto es, la comprensión que muestra don Juan Manuel sobre la cultura (el saber) como una suerte de instrumento de poder que lleva a la buena actuación política.

\section{Bibliografía}

Alfonso X, Primera crónica general de España: que mandó componer Alfonso el Sabio y se continuaba bajo Sancho IV en 1289, ed. Ramón Menéndez Pidal (Madrid: Gredos, 1955).

Alvar, Manuel, “Alfonso X contemplado por don Juan Manuel”, en Actas del Congreso Internacional La literatura en época de Sancho IV”, eds. Carlos Alvar y José Manuel Lucía Megías (Alcalá: Universidad de Alcalá, 1996), 91-106.

Bautista Crespo, Juan, "La Estoria de España y las crónicas generales," en Alfonso X el Sabio y las Crónicas de España, ed. Inés Fernández-Ordóñez (Valladolid: Centro para la Edición de los Clásicos Españoles, 2000), 107-132. 
Bautista, Francisco, "Juan Pineda, la Crónica Manuelina y la historiografía postalfonsí", Medievalia 19, 1 (2016): 7-32.

Benito-Vessles, Carmen, "Género literario y técnicas narrativas de la Crónica Abreviada", Crítica Hispánica 10, 1-2 (1988): 41-48.

Benito-Vessles, Carmen, "La prosa histórica de don Juan Manuel: la Crónica Abreviada y el Libro de las armas", en Actas del III Congreso de la Asociación Hispánica de Literatura Medieval, ed. M. Isabel Toro Pascua, vol. 1 (Salamanca: Universidad de Salamanca, 1994), 181-186.

Benito-Vessles, Carmen, Don Juan Manuel: escritura y recreación de la historia (Madison: Hispanic Seminary of Medieval Studies, 1994).

Catalán, Diego, "Don Juan Manuel ante el modelo alfonsí: el testimonio de la Crónica Abreviada", en Juan Manuel Studies, ed. Ian MacPherson (Londres: Tamesis, 1977), 17-51.

Catalán, Diego, De la silva textual al taller historiográfico alfonsí. Códices, crónicas, versiones y cuadernos de trabajo (Madrid: Fundación Ramón Menéndez PidalUniversidad Autónoma de Madrid, 1977).

Catalán, Diego, La Estoria de España de Alfonso X, creación y evolución (Valencia: Soler, 1992).

Don Juan Manuel, Obras completas, eds. Carlos Alvar y Sara Finci (Valencia: Proyecto Parnaseo, 2014).

Fernández-Ordóñez, Inés, "La historiografía alfonsí y post-alfonsí en sus textos. Nuevo panorama", Cahiers de linguistique hispanique médiévale, 18-19 (1993): 101-132.

Fernández-Ordóñez, Inés, "Variaciones en el modelo historiográfico alfonsí en el siglo XIII", en La historia alfonsí: el modelo y sus destinos, ed. Geroges Martin, (Madrid: Casa Velázquez, 2000), 41-74.

Funes, Leonardo, "Don Juan Manuel y la herencia alfonsí”, en Actas del VIII Congreso AHLMde la Asociación Hispánica de Literatura Medieval, eds. Margarita Freixas, Silvia Iriso Ariz, y Laura Fernández, vol. 1 (Santander: Consejería de CulturaAsociación Hispánica de Literatura Medieval, 2000), 781-788.

Funes, Leonardo, "Excentricidad y descentramiento en la figura autoral de don Juan Manuel", eHumanista, 9 (2007): 1-19.

Funes, Leonardo, "Historiografía nobiliaria castellana del período post-alfonsí: Un objeto en debate", La corónica 43, 1 (2014): 5-38.

Funes, Leonardo, "Historiografía nobiliaria del período post-alfonsí: un fenómeno histórico-literario en discusión", en Hispanismos del mundo. Diálogos y debates en (y desde) el sur, coord. Leonardo Funes (Buenos Aires: Miño y Dávila, 2016), 77-86. 
Funes, Leonardo, "La blasfemia del Rey Sabio itinerario narrativo de una leyenda (I)", Incipit, 13 (1993): 51-70.

Funes, Leonardo, "La blasfemia del rey Sabio itinerario narrativo de una leyenda (II)", Incipit, 14 (1994): 69-101.

Funes, Leonardo, "La leyenda de la blasfemia del Rey Sabio: revisión de su itinerario narrativo", e-Spania (2016), http://journals.openedition.org/e-spania/25873.

Funes, Leonardo, "Las letras castellanas en tiempos de Fernando IV: esbozo de una historia literaria", en El texto infinito: tradición y reescritura en la Edad Media y el Renacimiento, ed. Cesc Esteve (Salamanca: Seminario de Estudios Medievales y Renacentistas-Sociedad de Estudios Medievales y Renacentistas, 2014), 529-542.

Funes, Leonardo, "Materia legendaria en el discurso historiográfico del siglo XIV: la fantasía y la configuración literaria de una verdad histórica", en Fantasía y literatura en la Edad Media, eds. Miguel Nicasio Salvador, Santiago López Ríos y Esther Borrego Gutiérrez (Madrid: Iberoamericana-Vervuert, 2004), 163-178.

Funes, Leonardo, "Paradojas de la voluntad de autoría en la obra de Don Juan Manuel", en Actas del XIII Congreso de la Asociación Internacional de Hispanistas, eds. Florencio Sevilla y Carlos Alvar, vol. 1 (Madrid: Castalia, 2000), 126-133.

Funes, Leonardo, "Un lector calificado de la Estoria de Espanna alfonsí: el testimonio de La Crónica Abreviada de don Juan Manuel", en Studia Hispanica Medievalia II, eds. María A. Rosarossa y Rosa E. Penna (Argentina: Ergon 1992), 41-48.

Gayangos, Pascual, Escritores en prosa anteriores al XIV (Madrid: Biblioteca de Autores Españoles, 1860).

Gómez Redondo, Fernando, "Doña María de Molina y el primer modelo cultural castellano", en El intercambio artístico entre los reinos hispanos y las cortes europeas en la Baja Edad Media, coords. María C. Cosmen y otros (León: Universidad de León, 2009), 29-46.

Gómez Redondo, Fernando, "El molinismo: un sistema de pensamiento letrado (12841350)", en Estudios de literatura medieval: 25 años de la Asociación Hispánica de Literatura Medieval, coords. Antonia Martínez Pérez y Ana Luisa Baquero Escudero (Murcia: Universidad de Murcia, 2012), 45-81.

Gómez Redondo, Fernando, Fernando Gómez Redondo, Historia de la prosa medieval castellana. I. La creación del discurso prosístico: el entramado cortesano (Madrid: Cátedra, 1998).

González Mínguez, César, "Fernando IV de Castilla (1295-1312) perfil de un reinado", Espacio, tiempo y forma, 17 (2004): 223-244.

Hijano Villegas, Manuel, "El manuscrito Egerton 289 de la British Library y la Crónica Manuelina", e-Spania, 25 (2016), http://e-spania.revues.org/26096. 
Hijano Villegas, Manuel, "Fuentes romances de las crónicas generales: el testimonio de la Historia menos atajante", Hispanic Research Journal 12, 2 (2011): 129-131.

Hijano Villegas, Manuel, "Historia y poder simbólico en la obra de don Juan Manuel", Voz y Letrra 25, 1-2 (2014): 71-109.

Hijano Villegas, Manuel, "Monumento inacabado: la Estoria de Espana de Alfonso VII a Fernando III”, Cahiers d'études hispaniques médiévales 37, 1 (2014): 13-44.

Lacarra, María Jesús, "Don Juan Manuel (1282-1348): orgullo nobiliario y escritura", en Don Juan Manuel y su producción literaria, coord. María Jesús Lacarra (Valencia: Proyecto Parnaseo, 2014), 5-15.

Menéndez Pidal, Ramón, Le leyenda de los infantes de Lara (Madrid: Centro de Estudios Históricos, 1934).

Orduna, Germán, "Los prólogos a la Crónica abreviada y al Libro de la caza: la tradición alfonsí y la primera época en la obra literaria de don Juan Manuel”, Cuadernos de Historia de España, 51-52 (1970): 124-125.

Pattison, David G., "El Mío Cid del poema y el de las crónicas: evolución de un héroe", en El Cid: de la materia épica a las crónicas caballerescas, eds. Carlos Alvar y otros (Sevilla: Universidad de Alcalá, 2002), 23-27.

Powell, Brian, "British Library MS Egerton 289 and Santa Casilda", en Homenaje a Pedro Sainz Rodríguez, vol. 1 (Madrid: Fundación Universitaria Española, 1986), 3-14.

Salvador Moxó, "La nobleza castellana en el siglo XIV”, en Clásicos De Historia Social De España: Una Selección Crítica, comps. P. Sánchez León y J. Izquierdo (Valencia: Centro Francisco Tomás y Valiente-Fundación Instituto Historia Social, 2000), 87-116.

Saracino, Pablo Enrique, "La Crónica Abreviada de don Juan Manuel, una 'lectura desviada' de la Crónica Alfonsí", Medievalia, 38 (2006): 1-10.

Van Dijk, Teun A., Ideología y discurso (Barcelona: Ariel, 2003).

\section{Perfil académico}

José Ángel Salgado Loureiro es un investigador predoctoral de la Universidad de Santiago de Compostela. En ella obtuvo el grado en Historia (2013) y cursó el Máster Universitario en Estudios Medievales Europeos (2014). Entre sus temas de investigación está la historia de la cultura y el pensamiento político medievales y la historiografía del medievalismo español.

\section{Academic Profile}


José Ángel Salgado Loureiro is a predoctoral researcher at the University of Santiago de Compostela, where he obtained the degree in History (2013) and studied the Master Degree in European Medieval Studies (2014). Among his research topics are the history of medieval culture and political thought, and the historiography of Spanish medievalism.

Fecha de recepción: 3 de marzo de 2019.

Fecha de aceptación: 17 de diciembre de 2019.

Publicación: 31 de diciembre de 2019.

Para citar este artículo: José Ángel Salgado Loureiro, "La Crónica abreviada de don Juan Manuel en la historiografía post-alfonsí", Historiografías, 18 (julio-diciembre, 2019): pp. 91-111. 